\title{
Impact of Seasonal Variation in Food Availability and Disease Stress on the Health Status of Nomadic Turkana Children: A Longitudinal Analysis of Morbidity, Immunity, and Nutritional Status
}

\author{
BETTINA SHELL-DUNCAN \\ Population Studies Center, University of Michigan, Ann Arbor, Michigan \\ 48104-2590
}

\begin{abstract}
The possible influence of seasonal variations in rainfall, resource availability, and morbidity on immune function and nutritional status was examined in a longitudinal study of 54 nomadic Turkana children, 6 months to 10 years of age. The highly seasonal nature of rainfall in the arid semidesert environment of the Turkana District, northwestern Kenya, was associated with varying levels of animal milk production and meat and blood consumption. Despite significant seasonal variation in rainfall and food availability, the nutritional status of Turkana children, assessed through various anthropometric indicators, showed only moderate, if any, decline in the dry season. Rather, the data indicated that Turkana children suffer from chronic mild-to-moderate malnutrition. In addition, analyses of cellular immunocompetence of the children, recognized to be a functional index of nutritional status, revealed extremely high levels of immunosuppression year-round. Significant monthly variation in the levels of acute respiratory and gastrointestinal infections among children were found, although averages across seasons were not significantly different and did not correspond with fluctuations in rainfall or resource availability. Instead, periodic spikes in the prevalence of morbidity occurred against an already high level of infectious endemicity. The results indicate that food availability is not likely to be the sole determinant of nutritional status and that infection may be an important contributor to the high levels of nutritional and immunological stress among nomadic Turkana children. 1995 Wiley-Liss, Inc.
\end{abstract}

Seasonal fluctuations in nutritional status are important factors influencing the growth and well-being of children, particularly in populations with a high prevalence of mild-to-moderate undernutrition (Chen et al., 1979; Billewicz and McGregor, 1982; Brown et al., 1982). Acute nutritional deprivation is associated with elevated risk of morbidity and mortality, immunosuppression, and impaired mental development (Martorell and Ho, 1984; Martorell et al., 1992). Seasonal elevations of dietary and disease stresses are of particular interest since such fluctuations may precipitate the development of severe malnutrition among marginally malnourished children. Consequently, seasonal climatic variation may represent a significant risk factor in terms of child health and survival.

Repeated annual cycles of variation in nutritional status that are synchronized with patterns of rainfall have been documented in numerous populations throughout tropical and subtropical zones, although the observed patterns vary. In many regions inhabited by agriculturalists, the rainy season is accompanied by food shortages, increased labor demands, and a high prevalence of gastrointestinal infection. Consequently,

Received May 5, 1994; accepted November 14, 1994

Address reprint requests to $B$. Shell-Duncan. 
this period is associated with both weight loss in adults and reduced body mass and growth in children (Chen et al., 1979; Trowbridge and Newton, 1979; Billewicz and McGregor, 1982; Brown et al., 1982; Pagezy and Hauspie, 1985; Huss-Ashmore and Goodman, 1988; Cole, 1993). Conversely, in arid or semiarid savannah regions exploited by pastoralists, the critical period in terms of adult and child nutritional status is most frequently the dry season, characterized by reduced milk production, high temperatures and aridity, and increased energy expenditure associated with pasturing and watering herd animals (Loutan and Lamotte, 1984; Galvin, 1985; Hilderbrand, 1985; Lindtjorn et al., 1993). Given the diverse ecological and cultural contexts of such populations, the environmental stresses and behavioral adaptations influencing nutritional status would be expected to vary widely and would likely be mediated by multiple proximate biological determinants (Mosley and Chen, 1984).

As emphasized by Chen et al.(1979), nutritional status of children is determined not only by food availability, but also by foodrelated behaviors such as breastfeeding patterns and intrahousehold food distribution. In addition, numerous studies have documented the importance of infection, with seasonal patterns of occurrence, as an important, occasionally predominating determinant of nutritional status (Mata et al., 1972; Martorell et al., 1975; Rowland et al., 1977; Chen et al., 1979; Baumgartner and Pollitt, 1983; Tomkins, 1993). Furthermore, periods of nutritional stress are associated with increased susceptibility to and virulence of infectious disease. The increase in frequency and severity of infection is believed to be caused principally by suppression of the immune response, particularly cell-mediated immunity (CMI) (Koster et al., 1987). Several studies have confirmed that CMI function is readily impaired by even minor alterations in dietary adequacy as well as by infection (Smythe et al., 1971; Ziegler and Ziegler, 1975; Kauffman et al., 1976). Therefore, dramatic seasonal fluctuations in the level of nutritional and disease stress may severely affect the health and survival of children.

The purpose of this report is to identify the magnitude of seasonal fluctuations in health, immunocompetence, and nutritional status among nomadic Turkana children.
Using longitudinal data, this study attempts to delineate whether fluctuations in food supply and infectious morbidity correspond to variations in immunocompetence and nutritional well-being in children. Given that the environment which the Turkana inhabit is characterized by extreme seasonality in rainfall, it is hypothesized that food supplies, and consequently nutritional status and immune function, decline dramatically throughout the dry season. At the same time, morbidity from infectious disease is expected to increase as a result of deteriorated nutritional status and increased nutrition-related immunosuppression. Because of the difficulties in prospectively studying highly mobile populations inhabiting harsh and sparsely populated regions, relatively little is known about the magnitude of seasonal fluctuations in health and nutritional status in nomadic pastoralist populations. Although the topic of seasonality has in recent years received an increasing amount of attention (HussAshmore et al., 1988; Ulijaszek and Strickland, 1993), this issue is of central concern for nomadic pastoralists since their subsistence strategy is designed to exploit marginal and unpredictable environments. Furthermore, given that the settlement of pastoralist populatons is a major tenet of international dryland policy, arguing that sedentarization will result in nutritional and health benefits for the populations concerned (Fratkin, 1991; Galaty and Bonte, 1991), baseline information on the health status of traditional nomadic pastoralists is required to evaluate the impact of development efforts. The results identify the extent to which the dry season in Turkana is a critical period, in terms of child health and development, and outline the potential implications of seasonality for intervention and health care development programs in this region.

\section{STUDY POPULATION: THE TURKANA}

The Turkana are a tribe of traditional nomadic pastoralists, numbering $\sim 200,000$, who inhabit the arid semidesert region of northwestern Kenya. This study has evolved from previous research (Little and Leslie, 1990) focusing on one territorial subsection, the Ngisonyoka, who inhabit a southern region of the Turkana district bordered by the Turkwel and Kerio rivers on the north, west and east and the Turkana 


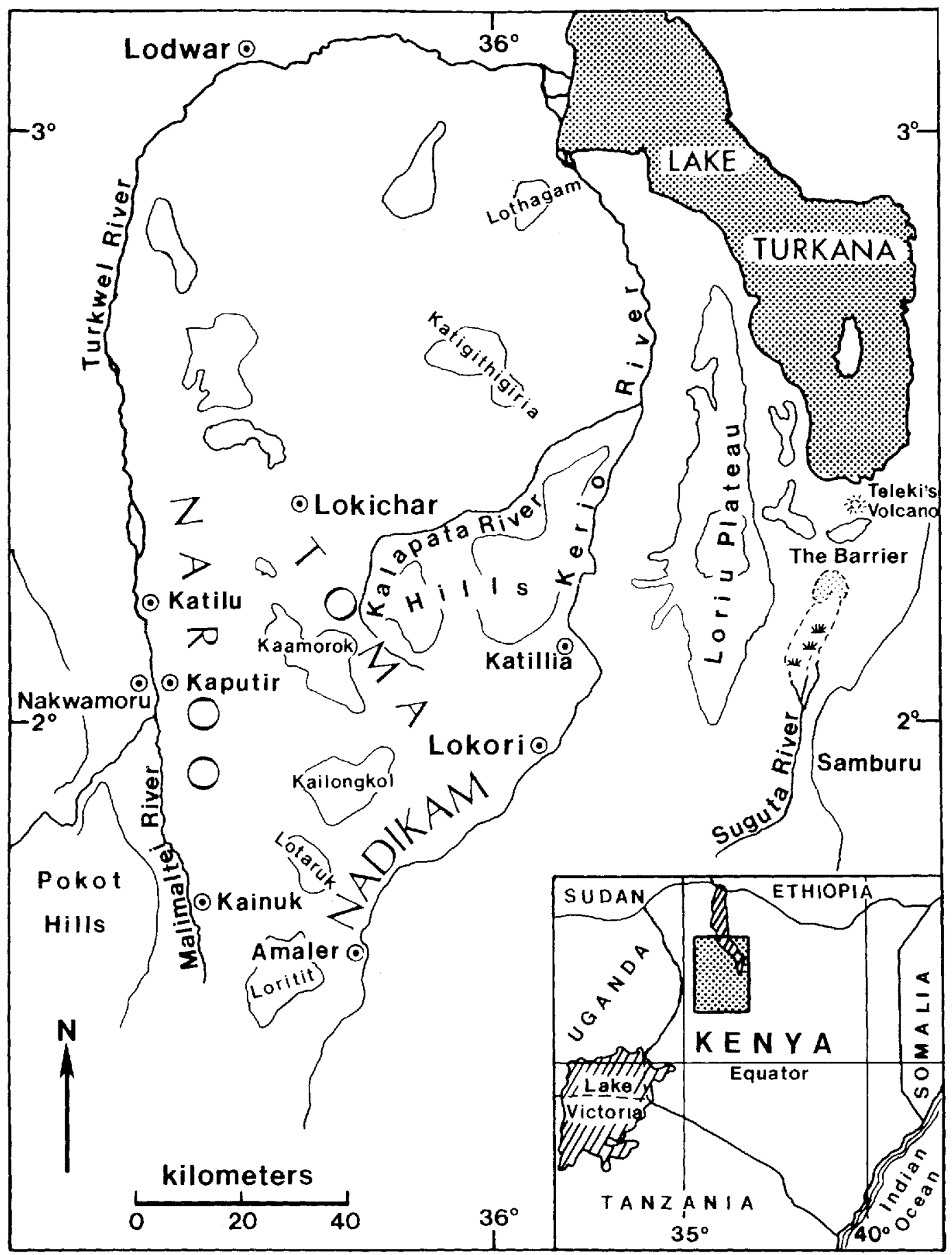

Fig. 1. Map of South Turkana. 
district border on the south (Fig. 1). The region is one of the harshest and least productive areas of East Africa, characterized by extreme heat and wind, aridity, periodic drought, and serious endemic diseases. Rainfall is $<300 \mathrm{~mm}$ per year and typically follows a bimodal pattern, with peaks in October to November (short rains) and April to May (long rains) (Galvin, 1985). However, the spatial and temporal distribution of rainfall is highly variable, and droughts are common.

The Turkana exploit this highly seasonal region by herding mixed stock, including camel, cattle, goats, sheep and donkey. To accommodate the different foraging and watering needs of each species, complex herding strategies, involving high mobility and herd fission and fusion based on species and production, are employed (McCabe et al., 1988). In the wet season, when forage and water are available in sufficient quantities, families and their herds congregate in neighborhoods or grazing associations called akakars and break up and become highly dispersed during the dry season. Because of the reliance on herd animals for subsistence, the demography of livestock and humans is closely linked.

The Turkana live in polygynous family units known as ngawei (s. awi), which are highly mobile and flexible in composition. Household members typically include a head herdowner, his wives, their sons and unmarried daughters, and possibly other extended family members such as half or full siblings and widowed parents. The household composition, however, frequently changes in an attempt to balance labor demands of herding with household consumption levels (Shell-Duncan, 1994a). Physically, the $a w i$ is a circular compound comprised of corrals, huts, and wind-breaks. Each woman with children has her own dayhut $(e k o l)$, which is the focus of social and domestic activities such as sewing, crafting vessels, and cooking. All residents of the awi are members of a particular woman's dayhut and are allocated food from that woman's resources. Each woman is independently responsible for fetching firewood and water and milking the animals assigned to her. Although milking animals may be borrowed, milk and milk products are rarely shared by women within the household (Galvin, 1985).
Nomadic Turkana are entirely dependent on their herds for subsistence, either directly from animal products or indirectly from animals exchanged for farm goods. Animal products of milk, blood, and meat comprise up to $80 \%$ of caloric intake, with milk contributing the major portion (Galvin, 1985). Consequently, dietary protein intake is adequate, although energy intake is very low. Because of the significant contribution of milk to total energy intake, the dry season, characterized by a dramatic reduction in the number of lactating animals and a decline in the quantity of milk production per head, is often a period of caloric deficit for many individuals. As milk availability decreases, energy intake is supplemented by an increased consumption of meat and blood, and farm products such as maizemeal, sugar, and millet, acquired from the sale of stock. These foods do not, however, entirely compensate for reduced milk availability, and seasonal declines in energy intake are found (Galvin, 1985). In an attempt to cope with reductions in food availability, the Turkana employ several behavioral strategies, such as reducing activity levels in the dry season, thereby lowering energy expenditure and altering intrahousehold food distribution, with preferential feeding of children. Despite these efforts, the Turkana suffer from chronic hypocaloric stress, with increases in caloric deficit in the dry season (Galvin, 1985).

Fluctuations in food availability may be a determinant of high infant and juvenile mortality rates among nomadic Turkana. Direct estimates of mortality are unavailable since accurate data on survivorship are difficult to obtain. Deaths are frequently underreported because of recall error and, more importantly, because of the painful nature of discussing children who have died. However, indirect measures suggest infant and juvenile mortality rates are very high, with estimates ranging between $25 \%$ and $36 \%$ (Brainard et al., 1986; Leslie 1988). Elevated nutritional stress during the dry season has been suggested as a possible determinant of high mortality (Brainard, 1986), and seasonal patterns of mortality may, in turn, contribute to monthly variation in birth rates. Whereas seasonality in vital event is found in almost all populations, the critical feature in Turkana is that climatic factors may be so strong as to be central in 
determining the level and pattern of mortality, nutrition, and disease.

\section{MATERIALS AND METHODS Subjects}

The data are from a 12-month longitudinal study of biological and sociocultural determinants of infant and childhood morbidity and mortality. Beginning in February 1990 , children and mothers from 15 nomadic families from the Ngisonyoka territorial subsection of the Turkana, ranging in size from 6 to 52 persons, were recruited to participate in one component of the study involving repeated assessment of nutritional status, morbidity, immune function, and resource availability over eight rounds of observation. Clusters of families from four different adakars (neighborhoods) were selected at the start of the rainy season. They are representative of the Ngisonyoka territorial subsection in terms of family size and composition, livestock holdings, and ties to the settled sector of the population. In all, 82 children between 6 months and 10 years of age were recruited, although there was some loss to follow-up because of migration to inaccessible regions. Fifty-four children were present for at least five of the first seven rounds of observation. Information on nutrition, health, and resource availability was collected from 37 mothers.

\section{Anthropometric data}

Nutritional status of the children and their mothers was assessed by examination for clinical signs of undernutrition (Jelliffe, 1966), and by anthropometry, including midupper arm circumference (MUAC), weight, and stature or length. All measurements were taken by a single observer using the techniques described by Jelliffe and Jelliffe (1989). MUAC was measured to the nearest $\mathrm{mm}$ with a plastic insertion tape. Stature was measured to the nearest $\mathrm{mm}$ with an anthropometer while subjects stood on a platform; recumbent length was recorded for subjects under $\sim 24$ months of age. Using a Health-o-meter beam scale, or a hanging weighing scale for infants, weight was measured to the nearest quarter pound and converted to kilograms. To assure quality of data, scales were routinely calibrated against known weights, and repeated measures were used to estimate measurement error. The standard deviation of single length and weight measurements were 0.56 $\mathrm{cm}$ and $0.31 \mathrm{~kg}$, respectively, and the standard deviation for MUAC was $0.11 \mathrm{~cm}$. Nude weight was easily obtained for small children, who wear little, if any, clothing. However, older children and women wear clothing and jewelry weighing up to several pounds. Each subject's apparel was noted at the time of measurement, and nude weight was estimated by deducting amounts of test weights of clothing and jewelry. To allow comparison of the anthropometry to reference data, ages were estimated through the use of an event history calendar established by Little and Leslie (1990). Because the Turkana have named annual seasons, which have been matched with seasonal and annual rainfall for over a decade (Little and Leslie, 1990), it is possible to pinpoint birthdates of young children with a high degree of accuracy for a nonliterate population with no system of birth registration. In addition, age estimates were verified by the ranking of children relative to one another, as well as to other children throughout the community, and by interviewing researchers and field assistants present in the study area at the time of birth of some subjects.

\section{Morbidity data}

Following the initial assessment of nutritional status in each round, approximate weekly reports of morbidity were collected for each child. Turkana classifications of symptoms and illness and traditional healing methods described by Shelley (1985) were used to interview women about the health history of their children. The number of episodes and duration were recorded for illness falling into one of seven disease categories: acute respiratory infection, gastroenteritis, eye infection, skin infection, malaria, unspecified fever, and other. Gastrointestinal infection was identified by the presence of three or more liquid stools per day, with or without vomiting. The length of each episode was defined as the number of consecutive days of diarrhea with no more than one interposed day lacking a liquid or semiliquid stool. Initially, any symptom of the upper or lower respiratory tract was defined as "respiratory illness." However, since these symptoms were chronic in many subjects, efforts were made to identify moderate and severe acute infections. An acute respiratory infection (ARI) was identified through 
symptoms of cough, rapid breathing, and fever. Each episode was separated by a minimal interval of 48 hours during which accompanying fever and body aches subsided. This method admittedly underestimates the true incidence rate of ARI since some severe infections are afebrile. Malaria was identified by the presence of fever and chills, vomiting, and liver and/or spleen enlargement. When symptoms of illness in each category were reported as ongoing at the time of interview, subjects were examined to confirm reported symptoms. Of reported malaria attacks, $62 \%$ were confirmed by thin smear, and $87 \%$ were accompanied by hepatomegaly or splenomegaly. The mother's impression of fever did not involve the use of a thermometer; examination of 38 subjects described as "hot" showed that $92 \%$ had body temperatures $>100.5^{\circ} \mathrm{F}$. For ethical reasons, minor first aid and oral rehydration therapy were provided for subjects when ill, thereby possibly influencing the duration of some disease episodes. In addition, professional medical treatment was sought for two subjects at the request of the investigator. No subjects died during the study period.

Progressively fewer bouts of illness were reported over longer time spans. This was interpreted to represent underreporting due to memory loss. To determine the maximum interval with adequate recall of health history, a subset of 18 subjects were examined daily, and their mothers were interviewed after 7-, 10-, 14-, 20-, and 30-day intervals. During recall periods of 10 days or less, the number of disease episodes and the number of days ill were underreported by $5.1 \%$ and $12.2 \%$, respectively. In intervals $>10$ days, underreporting rates rose dramatically, with attack rates underreported by $52 \%$ and number of days ill by $61 \%$ at 30 days. Therefore, only data from 10-day maximum intervals are presented.

\section{Immunocompetence}

Cell-mediated immunity (CMI) of children was assessed at two time periods, April and September, providing measures of immunocompetence in both the wet and dry seasons, respectively. CMI was measured by delayedtype hypersensitivity (DTH) testing, a procedure that involves the intradermal injection of test-recall antigens, which when reacting with T-lymphocytes, produces ervthematous induration within 24-48 hours. Details of this test procedure have been previously described (Shell-Duncan, 1993). DTH testing was conducted with the Multitest CMI ${ }^{\circledR}$ applicator (Merieux, France), which consists of eight sterile tines preloaded with seven test antigens and a glycerin negative control. Five of these antigens (Streptococcus, tuberculin, Candida, Trichophyton, and Proteus) and the glycerin control were administered to the taut volar surface of the forearm and allowed to remain on the skin surface for 3 minutes. The resulting induration was read at 48 hours with calipers measuring the diameter in $\mathrm{mm}$ in two perpendicular directions. The mean induration for each antigen was recorded, and the sum was reported as the cumulative induration size. In conformity with earlier studies, induration sies of $<2 \mathrm{~mm}$ are interpreted as negative (anergic) (Kniker et al., 1984). A total of 106 tests were administered, with repeat testing of 42 children. No child had ever been vaccinated, and none of the subjects suffered systemic reactions or exhibited a positive response to the glycerin control. The test antigens were stored between $2^{\circ}$ and $8^{\circ} \mathrm{C}$, and to assure potency, two applicators were tested on control subjects prior to each round of testing. All tests were administered and read by the investigator.

\section{Resource data}

At the outset of each round, mothers were interviewed regarding resources available over the preceding 30-day interval, including the number of milking animals, the frequency of bleeding animals, the number of animals slaughtered for meat, and the number of stock exchanged for consumption goods. These measures do not capture all sources of food acquisition since meat and store-bought foods are often exchanged among women within and between homesteads, and other family members who slaughter, milk, or bleed animals often individually consume at least some of the products before contributing them to the household. It is, however, assumed that these measures are general indicators of variation in food availability at the household (ekol) level since they have been found to correlate with measures of energy intake (Galvin, 1985). Data on rainfall at various meterological stations were obtained from the meterological office in Lodwar, Kenya. Estimates of 
rainfall are averages of readings from stations to which families were nearest each month.

\section{Analytical procedures}

The NCHS reference data (Hamill et al., 1979) were used to compute height-for-age, weight-for-age, and weight-for-height, expressed as standard deviations ( $Z$ scores) below reference values (Waterlow et al., 1977). This method has the advantage of having comparable reference limits across all indices and at all ages. In comparison to U.S. NHANES I data (Frisancho, 1981), MUACfor-age is expressed as a percentage of the median reference value. Whereas the use of international reference data may not be appropriate for the classification of nutritional status of Turkana children, it is useful for descriptive purposes, allowing contrasts of repeated measurements of growing children over a wide age range. Analyses of crosssectional measures of growth by Little et al. (1983) have indicated that over the age range of 1-10 years, the shape of growth curves for Turkana children is similar to that of the reference population, although at somewhat lower levels. Therefore, the $\mathrm{Z}$ scores and percentage of reference medians for repeat measures on each individual would be expected to be steady in the event of no seasonal change. To confirm the parallelism of growth curves of Turkana and U.S. children, $\mathrm{Z}$ scores were also computed for weight-for-age, height-for-age, and MUACfor-age children, aged $1-10$ years, using an independent sample of 217 nomadic Turkana children as a reference (Little et al., 1983). These data were collected in both wet and dry seasons and are believed to reperesent average values. It must be noted, however, that children were not screened by health status, and consequently the data do not necessarily represent average values for healthy, well-nourished children. In addition, because the Turkana reference data are available only for children $>11$ months of age, the sample of children for whom five or more repeat measures were available declined to 45. However, in the analysis of repeat measures using $Z$ scores obtained from both the Turkana and international reference data, similar results were obtained, confirming the validity of using international reference data to analyze the full sample of repeat measures collected in this study. Furthermore, the interaction terms between age and time could not be supported in each model tested due to multicollinearity, indicating the correlation between growth over time and age.

Trends in variation in both direct measures and derived anthropometric indices were examined for each child with an analysis of covariance model for repeat measures, described by Bock (1975). Using the BMDP statistical program (5V), missing values for individuals with up to two missing observations were imputed with the Expected Maximum Algorithm described by Little and Rubin (1987). This procedure assumes that missing values are "ignorable" in that missing data mechanisms are not selective in terms of nutritional status. Since children were lost to follow-up because of logistical problems associated with traveling long distances through rugged and remote terrain and not because of factors associated with food availability and nutritional status, this assumption is believed valid. The covariance structure for this ANCOVA procedure can be specified as compound symmetry, which assumes that the covariance between all possible pairs of repeat measures is equal, and consequently the covariance matrix of measures should have a constant diagonal and equal elements off the diagonal. Alternatively, the covariance structure can be unspecified, in which case all elements of the covariance matrix are estimated. Since the underlying covariance structure for each model was unknown, a likelihood ratio test of the null hypothesis that the covariance matrix has compound symmetry form versus the alternative hypothesis of unstructured covariance was performed. This test statistic is obtained by taking two times the difference in log-likelihood under the two models and is distributed as $\chi^{2}$. The prevalence of malnutrition among children, defined by MUAC-for-age and weight-forheight, was determined by comparing children to external reference data. Children falling below -3 s.d. in weight-forheight, or $75 \%$ of the reference median MUAC-for-age, were considered severely malnourished, whereas children between -2 and -3 s.d. in weight-for-height or between $75 \%$ and $80 \%$ of the reference median MUAC-for-age were classified as mild-tomoderately malnourished. The monthly proportions of children identified as malnour- 
ished by each indicator of nutritional status were compared by $x^{2}$ analysis.

Using data on 42 individuals measured during both of two rounds of DTH testing, the incidence of immunosuppression is calculated as the percentage of subjects with cumulative indurations below $2 \mathrm{~mm}$. Seasonal variation in immunocompetence was examined through McNamar's test of symmetry, which measures equality of change in one direction (anergic to not anergic) versus the opposite direction (not anergic to anergic).

Summary statistics of disease occurrence are expressed as an incidence rate, defined as the ratio of disease onsets in a population to the sum of days of surveillance (Rothman, 1986). The summation of time in the denominator is defined as "person-time" and can be expressed as a given amount of person-time, such as child-year (number of disease onsets per 365 days of observation) or child-month (number of disease onsets per 30 days of surveillance). In addition, information on the duration of illness is used to define the percent-time ill in a given amount of persontime. Monthly variation in the incidence of infectious illness is examined through analysis of variance.

Data on resource availability (number of milking animals, number of stock exchanged for food, number of animals rendered for meat, and number of animals bled) and household (ekol) consumption are used to derive measures of average monthly resource availability per person. Monthly levels of resource availability are compared through analysis of variance.

\section{RESULTS}

During the 12-month study period, the wet season occurred from February through April, during which time $70 \%$ of the total annual rainfall accumulated. A short wet season, which typically arrives in October or November, did not occur in this seasonal cycle (Figure 2). The decline in rainfall was accompanied by a statistically significant reduction in the number of milking animals per person (Fig. 3, top panel); this pattern is particularly evident in small stock $(\mathrm{F}=3.27, P<.01)$. Several attempts were made to compensate for reduced milk production in the dry months; the rendering (slaughter) rate, particularly of small stock, progressively increased in the dry season, as

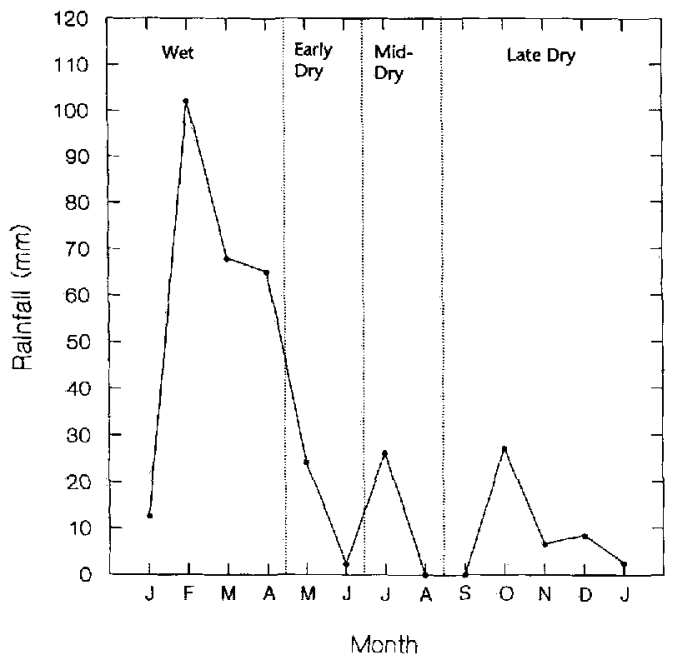

Fig. 2. Monthly variation in rainfall in South Turkana, January 1990 through January 1991.

did the frequency of bleeding animals and exchanging stock for farm food (Figure 3).

Table 1 summarizes infectious morbidity experienced by Turkana children. The most frequent categories of illness, in terms of the incidence and the number of days ill per child-year, were from acute respiratory infection, with an average of 16.64 attacks per child-year, and gastrointestinal infections, with 8.70 attacks per child-year. Although these figures cannot be compared directly to rates in other regions of the world because of differences in the definition of onset and termination of disease episodes, it suffices to note that the occurrences are high. Although the incidence rate for malaria is much lower than that for respiratory or gastrointestinal infections, the severity of this disease, particularly in young children, cannot be overlooked. Unfortunately, the sample size is too small to allow analyses of the pattern and impact of malarial infection.

Monthly variations in the incidence rates of ARI and gastroenteritis are shown in Figure 4. Although there is statistically significant monthly variation in attack rates for both gastroenteritis $(\mathrm{F}=3.01, P<.01)$ and ARI $(F=9.56, P<.01)$, these patterns do not correspond to variation in rainfall or milk availability. Interestingly, the largest peak in ARI occurred at the onset of the rainy season, although seasonal elevations occur most frequently in the dry season 

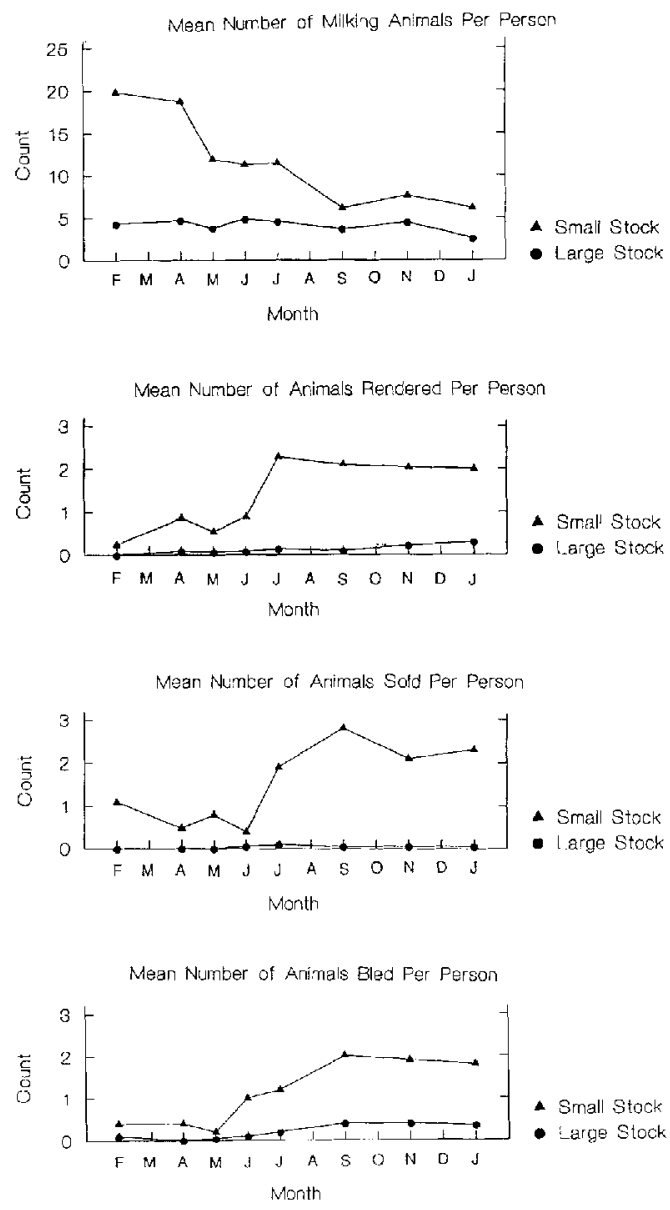

Fig. 3. Monthly variation in resource availability among 37 Turkana mothers from February 1990 through January 1991.

TABLE 1. Summary of morbidity among Turkana children $(n=54$, total days of surveillance $=6287)$

\begin{tabular}{lcc}
\hline Category of illness & $\begin{array}{c}\text { Mean number } \\
\text { of attacks } \\
\text { per child-year }\end{array}$ & $\begin{array}{c}\text { Mean number } \\
\text { of days } \\
\text { ill per } \\
\text { child-year }\end{array}$ \\
\hline $\begin{array}{l}\text { Acute respiratory } \\
\text { infection }\end{array}$ & 16.64 & 64.3 \\
Gastroenteritis & 8.70 & \\
Eye infection & 5.65 & 25.9 \\
Skin infection & 3.79 & 27.4 \\
Malaria & 1.44 & 17.0 \\
Unspecified fever & 1.39 & 6.4 \\
\hline
\end{tabular}

(Tomkins, 1993). This pattern may be attributable to the increased crowding of people in huts during the rains and more fre-
Incidence Rate of Acute Respiratory Infection
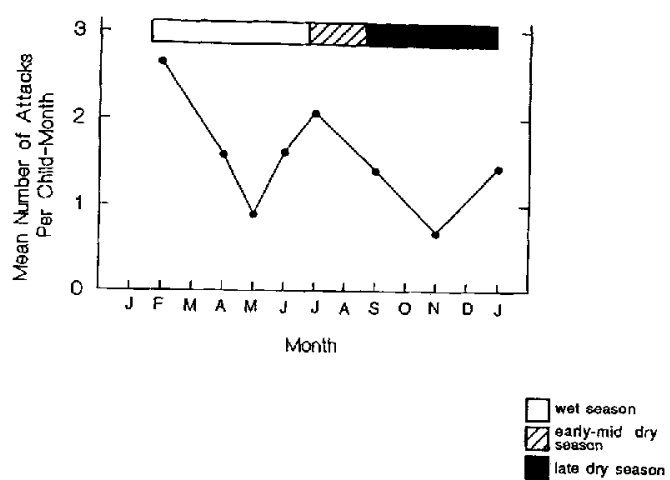

Incidence Rate of Gastroenteritis

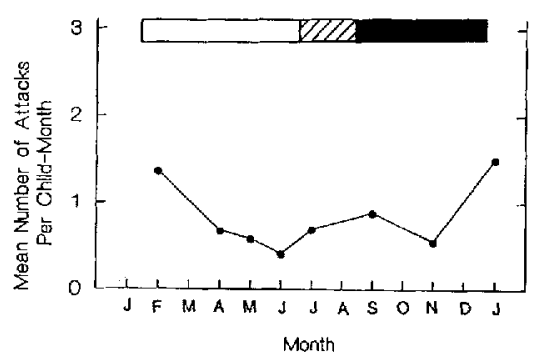

Fig. 4. Monthly variation in morbidity among Turkana children, ages 6 months to 10 years, from February 1990 through January 1991.

TABLE 2, Incidence ${ }^{1}$ of $A R I$ and gastroenteritis by season

\begin{tabular}{lcc}
\hline & ARI & Gastroenteritis \\
\hline Wet season & $\mathbf{1 . 7 4}$ & .79 \\
Early-mid dry season & 1.32 & .55 \\
Late dry season & 1.35 & .91 \\
\hline
\end{tabular}

${ }^{1}$ Mean number of attacks per child-month.

quent social gatherings of families. Two additional peaks occurred, one in the mid dry season in July, during which time a pertussis outbreak occurred, and the other at the late dry season in January. It should be noted, however, that these spikes occurred against a continuously high level of infection. Average rates across seasons (Table 2) are not significantly different. The monthly incidence of gastrointestinal infection showed a similar, although less dramatic, pattern of triple peaks, occurring in February, September, and January. Together, these figures demonstrate that Turkana 

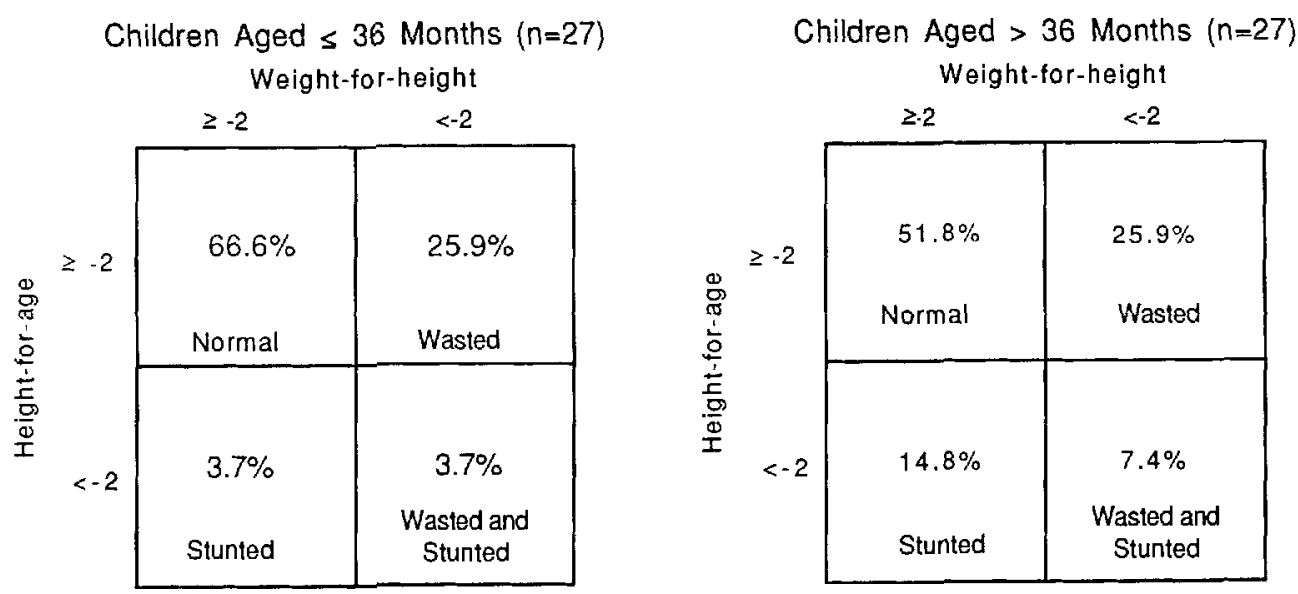

Fig. 5. Nutritional status profile of children, 6 months to 10 years, at the time of recruitment in February 1990.

children chronically suffered from frequent attacks of infectious disease.

The nutritional characteristics of the subjects at the time of recruitment in February 1990, are summarized in Figure 5. Using the Waterlow (1977) classification system, it can be seen that a large fraction of children in both older and younger age groups were wasted (or thin) at the time of recruitment, whereas a relatively large proportion of older children ( $>36$ months) were stunted compared to younger children $\quad(\leqslant 36$ months). It is important to stress that this classification is simply descriptive, as cutoff values for identifying elevated risk groups and grades of malnutrition are not known for this population.

To determine the degree of growth over the study period, an ANCOVA for repeat measures (Bock, 1975) was performed, estimating the effect of time (season) and controlling for the effects of age, sex, and interactions between sex and time. The BMDP statistical program (5V) was used to compute maximum likelihood estimates of parameters of a model in which expected values of anthropometric measures over time are described by a function (linear, quadratic, or cubic) of the regression parameters. Complete data over seven rounds of observation were available for 30 individuals. Missing values were imputed for an additional 24 subjects, who were available for at least five rounds of observation, with an Expected Maximization Algorithm described by Little and Rubin (1987). Likelihood ratio tests for the covariance structure of each model were highly significant, indicating that the covariance matrix does not have the compound symmetry form. Estimates of the regression parameters for models with unstructured covariance are shown in Table 3. Age at the time of recruitment, rather than age at the time of each measurement, was used as a covariate to avoid confounding the effect of time (season). In the original model, an interaction term between age and time was included; this model, however, could not be supported because of multicollinearity. The results indicated that, using a linear model, children exhibited statistically significant ponderal and linear growth and gains in the BMI. The coefficients for the effect of time indicated that over the 10month study period children gained, on average, $2.2 \mathrm{~kg}(3.2 \%)$ in weight, $5.2 \mathrm{~cm}(7.4 \%)$ in height, and $0.7 \mathrm{~kg} / \mathrm{m}^{2}(2.7 \%)$ in BMI. MUAC significantly declined over the study period, although the actual magnitude of the decline was quite small $(0.37 \mathrm{~cm}$, or $2.7 \%)$.

To determine whether nutritional status showed significant seasonal variation, four anthropometric indices derived from international reference data (weight-for-age, heightfor-age, weight-for-height, and MUAC-forage) were also analyzed through ANCOVA for repeated measures (Fig. 6). The results using a linear model with unstructured covariance (Table 4) indicated no significant variation over time in weight-for-age; similar negative 
TABLE 3. Maximum likelihood estimates of regression parameters for an analysis of covariance for repeated measures for anthropometric dimensions

\begin{tabular}{|c|c|c|c|c|}
\hline $\begin{array}{l}\text { Dependent variable: Weight }(\mathrm{kg}) \\
\text { Parameter }\end{array}$ & Estimate & Asymptotic SE & Z-Score & $\begin{array}{c}\text { Two-sided } \\
\text { P-value }\end{array}$ \\
\hline $\begin{array}{l}\text { Constant } \\
\text { Time } \\
\text { Age } \\
\text { Sex } \\
\text { Sex time }\end{array}$ & $\begin{array}{r}6.98007 \\
.22557 \\
.11489 \\
.17974 \\
-.01434\end{array}$ & $\begin{array}{l}.37027 \\
.01824 \\
.00707 \\
.22681 \\
.01824\end{array}$ & $\begin{array}{r}18.851 \\
12.366 \\
16.258 \\
.794 \\
-.786\end{array}$ & $\begin{array}{l}.0001 \\
.0001 \\
.0001 \\
.4281 \\
.4316\end{array}$ \\
\hline $\begin{array}{l}\text { Dependent variable: Height }(\mathrm{cm}) \\
\text { Parameter }\end{array}$ & Estimate & Asymptotic SE & Z-score & $\begin{array}{c}\text { Two-sided } \\
\text { P-value }\end{array}$ \\
\hline $\begin{array}{l}\text { Constant } \\
\text { Time } \\
\text { Age } \\
\text { Sex } \\
\text { Sex time }\end{array}$ & $\begin{array}{r}69.88849 \\
.52028 \\
.51243 \\
.78966 \\
.03054\end{array}$ & $\begin{array}{r}1.23856 \\
.03460 \\
.02423 \\
.73304 \\
.03460\end{array}$ & $\begin{array}{r}56.427 \\
15.038 \\
21.149 \\
1.077 \\
.883\end{array}$ & $\begin{array}{l}.0001 \\
.0001 \\
.0001 \\
.2814 \\
.3774\end{array}$ \\
\hline $\begin{array}{l}\text { Dependent variable: MUAC }(\mathrm{cm}) \\
\text { Parameter }\end{array}$ & Estimate & Asymptotic SE & Z-score & $\begin{array}{c}\text { Two-sided } \\
\text { P-value }\end{array}$ \\
\hline $\begin{array}{l}\text { Constant } \\
\text { Time } \\
\text { Age } \\
\text { Sex } \\
\text { Sex time }\end{array}$ & $\begin{array}{r}13.98298 \\
-.03703 \\
.01567 \\
.04481 \\
-.00175\end{array}$ & $\begin{array}{l}.20695 \\
.00988 \\
.00401 \\
.12334 \\
.00989\end{array}$ & $\begin{array}{r}67.566 \\
-3.746 \\
3.903 \\
.363 \\
-.017\end{array}$ & $\begin{array}{l}.0001 \\
.0002 \\
.0001 \\
.7164 \\
.8596\end{array}$ \\
\hline $\begin{array}{l}\text { Dependent variable: BMI }\left(\mathrm{kg} / \mathrm{m}^{2}\right) \\
\text { Parameter }\end{array}$ & Estimate & Asymptotic SE & Z-score & $\begin{array}{c}\text { Two-sided } \\
\text { P-value }\end{array}$ \\
\hline $\begin{array}{l}\text { Constant } \\
\text { Time } \\
\text { Age } \\
\text { Sex } \\
\text { Sex time }\end{array}$ & $\begin{array}{r}14.94292 \\
.07367 \\
-.02256 \\
.21413 \\
-.02756\end{array}$ & $\begin{array}{l}.28770 \\
.02707 \\
.00492 \\
.20357 \\
.02707\end{array}$ & $\begin{array}{r}51.938 \\
2.721 \\
-4.584 \\
1.052 \\
-1.018\end{array}$ & $\begin{array}{l}.0001 \\
.0065 \\
.0001 \\
.2929 \\
.3087\end{array}$ \\
\hline
\end{tabular}

results were obtained with quadratic and cubic models. The other three indices, weightfor-height, height-for-age, and MUAC-for-age, showed significant linear variation over time. However, whereas MUAC-for-age and heightfor-age decreased as the dry season progressed, weight-for-height increased. Notably, the coefficients for the effect of time on each of the indicators showed that the actual magnitude of change across season was moderate; on average, over the 10-month observation period children lost $0.33 \mathrm{SD}$ units in height-forage, $6.6 \%$ of reference MUAC-for-age, and gained $0.61 \mathrm{SD}$ units in weight-for-height. For MUAC-for-age, age at the time of recruitment had a significant negative effect, indicating that older children showed greater seasonal declines in MUAC than younger children. There were no differences by sex.

Compared to international reference data for weight-for-height and MUAC-for-age, a large proportion of the children suffered from mild-to-moderate undernutrition yearround (Fig. 7). However, the two systems of classification did not agree on seasonal differences in the prevalence of undernutrition. The proportion of malnourished children defined by weight-for-height did not vary significantly over time, whereas undernutrition, defined by MUAC-for-age, progressively increased $\left(\chi^{2}=16.34, P<.05\right)$ over time. The proportion of children below $80 \%$ of expected MUAC-for-age varied from $3.9 \%$ to $25.6 \%$. These figures must be interpreted cautiously since no criteria exist for the selection of cutoff points for grading degrees of malnutrition. As proposed by Trowbridge and Staehling (1980), low cutoff values for MUAC-for-age and weight-for-height were selected in an effort to maximize specificity, defined as the percentage of true negatives for malnutrition. The finding of low levels of severe undernutrition among Turkana children was supported by data on 

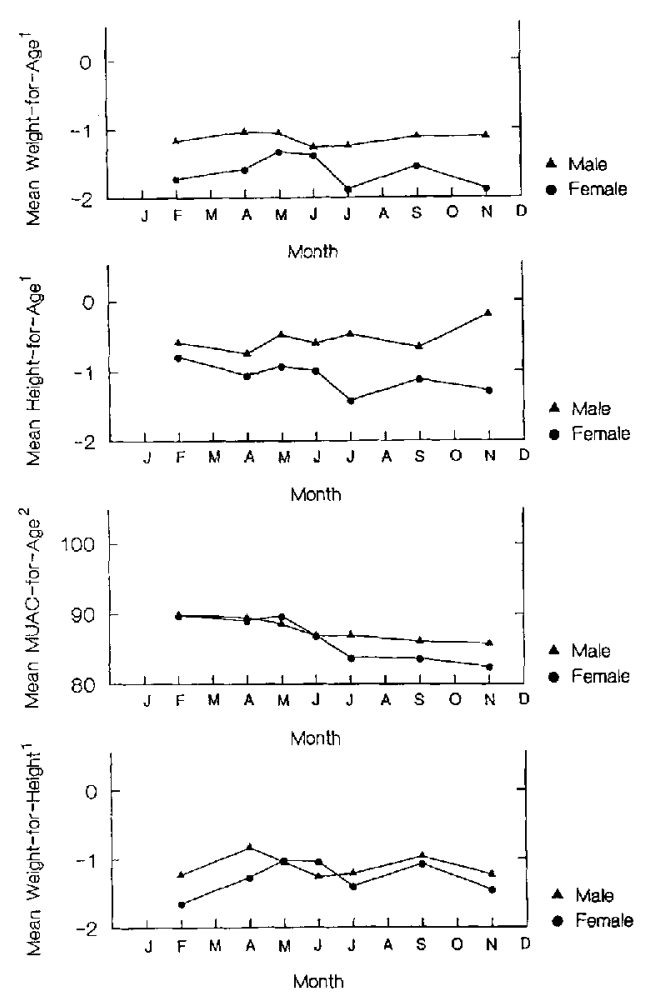

1 Z-Score. NCHS Reterence data

2 Percent of mean relerence value, U.S. NHANES I Data

Fig. 6. Monthly variation in anthropometric indices derived from international reference data, of Turkana children 6 months to 10 years, from February through November, 1990.

clinical signs of undernutrition; a small proportion of subjects, exhibited symptoms potentially indicating severe protein-energy malnutrition (muscle wasting and dyspigmentation of the hair) (Table 5). The majority of recorded symptoms were likely caused by poor sanitation, environmental insults such as wind, heat, and aridity, or by infection.

Seasonal variation in immunoresponsiveness was examined in 42 children administered DTH tests in both the wet and dry seasons. The incidence of immunosuppression was extremely high in both seasons; $59.5 \%$ and $54.8 \%$ of the children tested negative ( $<2 \mathrm{~mm}$ induration) in the wet and dry seasons, respectively. As none of the children were vaccinated and complete medical histories did not exist, it was impossible to calculate the total number of false-negative readings. The results were, however, substantiated by the fact that of the 17 children who tested positive in the wet season, $47.1 \%$ later tested negative (Fig. 8). The effect of season on immunocompetence was analyzed through McNamar's test of symmetry, which measures whether, in repeat rounds of measurement, change in one direction (positive to negative) is equal to change in the other direction (negative to positive). The results were not significant $\left(\chi^{2}=.222\right.$, $P=.637$ ), indicating no improvement or decline in immunocompetence across seasons.

\section{DISCUSSION}

This study longitudinally assessed the effect of season on indicators of health status of nomadic Turkana children, including nutritional status, immunocompetence, and infectious morbidity. Over the 12-month observation period, the amount of rainfall and availability of resources fluctuated dramatically. Despite the significant variation in food availability at the household level, the nutritional status of the children showed only moderate change across seasons. Analysis of repeated measures of weight, height and BMI indicated that children continued to grow over the study, although MUAC, on average, declined. To assess the adequacy of growth, derived indices from measures of weight and height were analyzed through ANCOVA for repeated measures and showed different trends: weight-for-age showed no significant change over time, whereas height-for-age declined and weightfor-height increased. Such a pattern may be expected when growth in weight remains steady and normal, and growth in height decelerates. In general, growth in height, expressed as height-for-age, reflects longterm trends in nutritional status, whereas growth in weight, expressed as weight-forheight and weight-for-age, is sensitive to short-term changes and reflects current nutritional status. Although growth in height is relatively insensitive to acute nutritional stress, seasonal patterns are commonly observed in absence of variation in levels of dietary or disease stress (Bogin, 1978). It seems, therefore, that a period of minimal growth in height among Turkana children was not caused by, but coincided with, the dry season. Furthermore, growth in weight and improved weight-for-height status may not clearly represent adequacy of nutri- 
TABLE 4. Maximum likelihood estimates of regression parameters for an analysis of covariance for repeated measures using $Z$-scores and percentage of reference medians from international reference data

\begin{tabular}{|c|c|c|c|c|}
\hline $\begin{array}{l}\text { Dependent variable: Weight-for-age } \\
\text { Parameter }\end{array}$ & Estimate & Asymptotic SE & Z-score & $\begin{array}{c}\text { Two-sided } \\
\text { P-value }\end{array}$ \\
\hline $\begin{array}{l}\text { Constant } \\
\text { Time } \\
\text { Age } \\
\text { Sex } \\
\text { Sex time }\end{array}$ & $\begin{array}{r}-.89981 \\
.01907 \\
-.01106 \\
.11871 \\
-.00879\end{array}$ & $\begin{array}{l}.22528 \\
.01440 \\
.00386 \\
.15872 \\
.01440\end{array}$ & $\begin{array}{r}-3.994 \\
1.325 \\
-2.863 \\
.748 \\
-.611\end{array}$ & $\begin{array}{l}.0001 \\
.1853 \\
.0042 \\
.4545 \\
.5415\end{array}$ \\
\hline $\begin{array}{l}\text { Dependent variable: Height-for-age } \\
\text { Parameter }\end{array}$ & Estimate & Asymptotic SE & Z-score & $\begin{array}{c}\text { Two-sided } \\
\text { P-value }\end{array}$ \\
\hline $\begin{array}{l}\text { Constant } \\
\text { Time } \\
\text { Age } \\
\text { Sex } \\
\text { Sex time }\end{array}$ & $\begin{array}{r}-.56981 \\
-.03303 \\
-.00185 \\
.08295 \\
.01190\end{array}$ & $\begin{array}{l}.27284 \\
.01464 \\
.00489 \\
.18800 \\
.01464\end{array}$ & $\begin{array}{r}-2.088 \\
-2.256 \\
-.379 \\
.441 \\
.813\end{array}$ & $\begin{array}{l}.0368 \\
.0241 \\
.7050 \\
.6590 \\
.4163\end{array}$ \\
\hline $\begin{array}{l}\text { Dependent variable: MUAC-for-age } \\
\text { Parameter }\end{array}$ & Estimate & Asymptotic SE & Z-score & $\begin{array}{c}\text { Two-sided } \\
\text { P-value }\end{array}$ \\
\hline $\begin{array}{l}\text { Constant } \\
\text { Time } \\
\text { Age } \\
\text { Sex } \\
\text { Sex time }\end{array}$ & $\begin{array}{r}96.17234 \\
-.66171 \\
-.11146 \\
-.99639 \\
.12655\end{array}$ & $\begin{array}{r}1.41491 \\
.06645 \\
.02698 \\
.87005 \\
.06647\end{array}$ & $\begin{array}{r}67.991 \\
-9.958 \\
-4.131 \\
-1.145 \\
1.904\end{array}$ & $\begin{array}{l}.0001 \\
.0001 \\
.0001 \\
.2521 \\
.0569\end{array}$ \\
\hline $\begin{array}{l}\text { Dependent variable: Weight-for-height } \\
\text { Parameter }\end{array}$ & Estimate & Asymptotic SE & Z-score & $\begin{array}{l}\text { Two-sided } \\
\text { P-value }\end{array}$ \\
\hline $\begin{array}{l}\text { Constant } \\
\text { Time } \\
\text { Age } \\
\text { Sex } \\
\text { Sex time }\end{array}$ & $\begin{array}{r}-1.37031 \\
.06144 \\
-.00391 \\
.09149 \\
-.00937\end{array}$ & $\begin{array}{l}.21126 \\
.01706 \\
.00364 \\
.14807 \\
.01706\end{array}$ & $\begin{array}{r}-6.486 \\
3.601 \\
-1.076 \\
.618 \\
-.549\end{array}$ & $\begin{array}{l}.0001 \\
.0003 \\
.2820 \\
.5366 \\
.5829\end{array}$ \\
\hline
\end{tabular}

tional status in Turkana children. Trowbridge et al. (1987) have shown that increased weight-for-height in undernourished Peruvian children does not reflect improved nutrition or increased body fat, but rather is associated with an increase in the hydration of fat-free tissue related to malnutrition. This response may occur seasonally among marginally nourished Turkana children, although further research is required to confirm this pattern.

MUAC-for-age was also used to assess seasonal variation in the nutritional status of children. This measure is much less sensitive to hydration and is reported to reflect wasting in a manner similar to weight-forage (Shakir and Morley, 1974; Shakir, 1975) and weight-for-height (McDowell and King, 1982), although these findings have met criticism (Vijayaraghavan and Sastry, 1976; Margo, 1977; El-Nofely et al., 1993). Analyses showed that MUAC-for-age declined sig- nificantly through the dry months, with children losing, on average, $6.6 \%$ of expected MUAC-for-age.

Given the pattern of extreme seasonality in rainfall and resource availability, it is at first surprising to find only moderate fluctuations in nutritional status of Turkana children. However, the effects of reduced food availability at the household (ekol) level may be attenuated through feeding practices that buffer individuals most vulnerable to malnutrition. Galvin (1985) reported that Turkana mothers attempt to minimize the impact of food shortages on children by reducing their own dietary intake and preferentially feeding their children. Data on weight change among mothers supports this finding since mothers lost $1.5 \mathrm{~kg}(3.3 \%$ of total body weight) over the 10-month study period (Shell-Duncan, 1994b). It is important to note that although children's nutritional status did not dramatically decline in 
Weight-for-Height

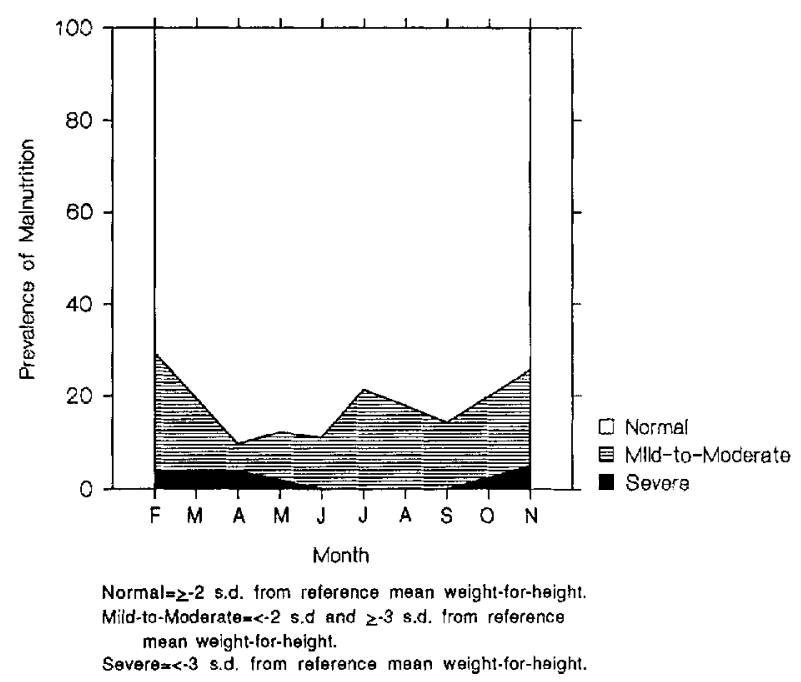

MUAC-for-Age

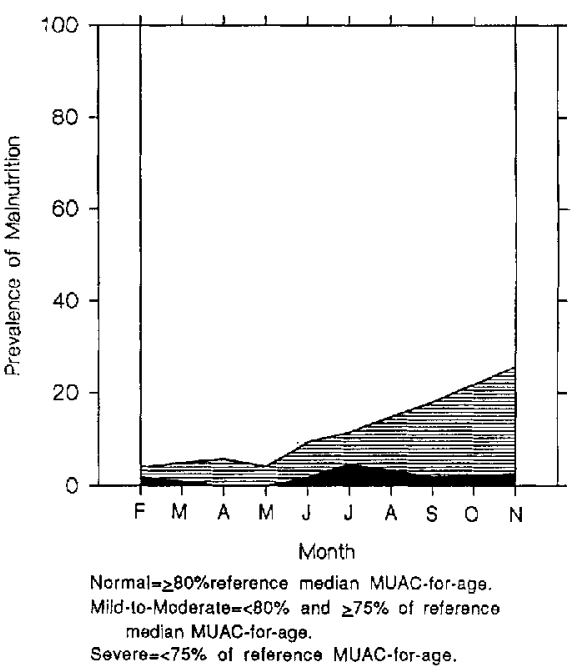

Fig. 7. Prevalence of undernutrition defined by two anthropometric dimensions in Turkana children from February through November, 1990.

TABLE 5. Seasonal prevalence of clinical signs potentially indicating malnutrition among children

\begin{tabular}{lcc}
\hline Symptom & $\begin{array}{c}\text { Wet season } \\
\text { (Apri) } \\
\text { (n = 54) }\end{array}$ & $\begin{array}{c}\text { Dry season } \\
\text { (September) } \\
\text { ( } \mathbf{n}=\mathbf{5 2})\end{array}$ \\
\hline Hepatomegaly & 27.7 & 11.5 \\
Pale conjunctiva & 27.7 & 5.8 \\
Bitot's spots & 25.9 & 28.8 \\
Splenomegaly & 18.5 & 11.5 \\
Xerosis of the skin & 18.5 & 19.2 \\
Xerosis conjunctivae & 14.8 & 26.9 \\
Muscle wasting & 1.9 & 3.9 \\
Hair dyspigmentation & 1.9 & 3.9 \\
\hline
\end{tabular}

the dry season, it was not, on average, adequate. Evidence suggesting that Turkana children suffer from chronic mild-to-moderate malnutrition are summarized in Table 6. Serial measurements were used to estimate the prevalence of undernutrition. The results of this study are consistent with those of Galvin (1985), showing that, in comparison to international reference data, a large proportion of Turkana children are chronically undernourished. The proportion of children below $80 \%$ of expected MUAC-forage ranged between $3.9 \%$ and $25.6 \%$ over the study period, and the proportion of children more than 2 SDs below mean reference weight-for-height ranged between $9.6 \%$ and $29.4 \%$. Further evidence of chronic mild-to-

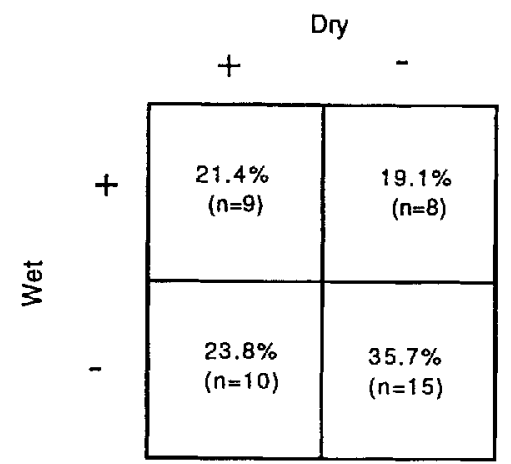

$+=z 2 \mathrm{~mm}$ cumulative induration

$-=<2 \mathrm{~mm}$ cumulative induration

Fig. 8. Cross-tabulation of positive $(t)$ and negative (-) DTH skin test responses of 42 Turkana children, ages 6 months to 10 years, tested in both the wet season (April 1990) and the dry season (September 1990).

moderate undernutrition is a slow and prolonged pattern of growth in weight and height (Little and Johnson, 1987); such patterns are characteristic of populations with chronic low dietary intakes (Eveleth and Tanner, 1986; Satyanarayana et al., 1980; Bailey et al., 1984). In addition, using estimates of dietary intake and energy expenditure, Galvin (1985) showed that Turkana 
TABLE 6. Evidence of chronic mild-to-moderate undernutrition among Turkana children

\begin{tabular}{|c|c|c|}
\hline Indicator & Assessment & Reference \\
\hline 1. Longitudinal anthropometry & $\begin{array}{l}\text { A high prevalence of } \\
\text { mild-to-moderate malnutrition, } \\
\text { with little seasonal variation }\end{array}$ & Galvin (1985) and present study \\
\hline $\begin{array}{l}\text { 2. Mixed-longitudinal } \\
\text { anthropometry }\end{array}$ & Slow, prolonged growth & Little and Johnson (1987) \\
\hline $\begin{array}{l}\text { 3. Longitudinal estimates of dietary } \\
\text { intake and energy expenditure }\end{array}$ & Chronic hypocaloric stress & Galvin (1985) \\
\hline $\begin{array}{l}\text { 4. DTH tests of cell-mediated } \\
\text { immunocompetence }\end{array}$ & $\begin{array}{l}\text { High levels of immunosuppression } \\
\text { in both wet and dry seasons }\end{array}$ & Present study \\
\hline
\end{tabular}

children experience chronic hypocaloric stress, with occasional periods of caloric deficit. Finally, analyses of cellular immunocompetence, a functional index of nutritional status (Chandra, 1981), revealed extremely high levels of immunosuppression year-round; $59.5 \%$ of the children were anergic in the wet season and $54.8 \%$ were anergic in the dry season.

Given that children did not show evidence of strong nutritional or immunological decline during the dry season months, adequacy of food intake is not likely to be the sole determinant of nutritional status. Data showed that the pattern of extreme seasonality in rainfall and resource availability was superimposed on a situation of serious endemic disease. The most frequent cause of infectious illness was acute respiratory infection, with each child suffering an average of 16.64 episodes per child-year, followed by gastrointestinal infection, with an incidence rate of 8.70 episodes per child-year. Studies of morbidity in regions characterized by moderate or high seasonality have shown patterns of infection corresponding to climatic factors, such as rainfall, humidity, and temperature. Typically, the prevalence of respiratory infections peak in the dry season due to factors such as increased wind and dust, dryness-related alterations in the epithelium of the respiratory tract, and increased crowding (Chambers et al., 1981; Blakeborough et al., 1982; Tomkins, 1993). Conversely, epidemics of diarrheal disease are more frequent in the rainy season due to factors such as moist conditions favoring the survival and proliferation of pathogenic organisms, surface runoff water contaminating drinking water supplies with fecal bacteria, and increased fly counts causing the spread of bacterial pathogens, particularly dysenteric organisms (Poskitt, 1972; Chen et al., 1979; Trowbridge and Newton, 1979; Billewicz and McGregor, 1982; Tomkins,
1993). Although the prevalence of infection in Turkana showed significant monthly variation, patterns of morbidity did not correspond to climatic variations over the course of the study period. Rather, peaks in prevalence occurred against an already high level of infectious endemicity. High levels of infection have the potential to alter nutritional well-being through the elevation of metabolic rates, nutrient wastage, and anorexia (Mata et al., 1972). The resulting nutritional stress, as well as infection itself, are known causes of impaired immune function. Consequently, subjects are at an elevated risk of repeated or secondary infection, and the two-way interaction between nutrition and infection is promoted.

The results of this study have practical as well as theoretical significance. Data on morbidity suggest that nutritional intervention efforts involving food distribution alone may be inadequate as nutrient wastage from infection is an important contributor to nutritional stress. Although further investigations including larger numbers of children are needed to confirm the generalizability of findings reported here, it seems certain that intensification of current efforts to vaccinate children in the nomadic sector of the Turkana population have strong potential for dramatically improving their well-being and chances of survival.

In summary, the nutritional status of nomadic Turkana children observed over the course of this study is characterized by a moderate degree of seasonal variation. This result is surprising given that the Turkana inhabit a marginal and highly seasonal environment, characterized by significant variation in rainfall and, consequently, resource availability. Although seasonal factors may be strong among the Turkana, they were not the predominant determinants of health status of children in this study. Rather, the evidence suggests that Turkana 
children suffer from chronic mild-to-moderate undernutrition and immunosuppression, which may be related to serious endemic disease and year-round hypocaloric stress. Analyses of the nature of the interactions among nutrition, immunity, and morbidity will be reported in the future.

\section{ACKNOWLEDGMENTS}

I am grateful to the many people who assisted in the design and implementation of this research, including $\mathrm{Mr}$. Warren Becker, Ms. Jennifer Bush, Ms. Leah Imoru Lobar, Mr. Michael O'Neill, Dr. Richard Wilson, and Dr. James Wood. This research was conducted as part of the South Turkana Ecosystem Project, and the leaders of this project, Dr. Michael Little and Dr. Paul Leslie, kindly provided research affiliation as well as support in the field. I thank the Hon. S.M. Toyya, District Commissioner, and the Turkana District Officers for their cooperation. The Population Studies Center at the University of Michigan afforded affiliation and computer support during data analysis, and Dr. Kathleen Welch provided valuable statistical advice. I also thank Dr. Roberto Frisancho for his advice on interpreting anthropometric data. Funding for this research was provided by the National Science Foundation Grants BNS-89144312 and DBS-9207837, the Wenner-Gren Foundation for Anthropological Research, the Sigma Xi Scientific Research Society, the Hill Foundation, and the Biomedical Research Support Fund at the Pennsylvania State University.

\section{LITERATURE CITED}

Bailey SM, Gershoff SN, McGandy RB, Nondasuta A, Tantiwongse P, Suttapreyasri D, Miller J, McCree P (1984) A longitudinal study of growth and maturation in rural Thailand. Hum. Biol. 56:539-557.

Baumgartner RN, Pollitt E (1983) The Bacon Chow Study: Analyses of the effects of infectious illness on growth of infants. Nutr. Res. 3:9-21

Billewicz WA, McGregor LA (1982) A birth-to-maturity longitudinal study of heights and weights in two West African (Gambian) villages, 1951-1975. Ann. Hum. Biol. 9:309-320.

Blakeborough IS, Greenwood BM, Whittle HC, Bradley AK, Gilles HM (1982) The epidemiology of Neisseria meningitis and Neisseria lactamica in a northern $\mathrm{Ni}$ gerian community. J. Inf. Dis. 146:626-637.

Bock RD (1975) Multivariate Statistical Methods in Behavioral Research. New York: McGraw-Hill.

Bogin BA (1978) Seasonal pattern in the rate of growth in height of children living in Guatemala. Am. J. Phys. Anthropol. 49:205-210.

Brainard JM (1986) Differential mortality in Turkana agriculturalists and pastoralists. Am. J. Phys. Anthropol. 70:525-536.
Brown KH, Black RE, Becker S (1982) Seasonal changes in nutritional status and the prevalence of malnutrition in a longitudinal study of young children in rural Bangladesh. Am. J. Clin. Nutr. 36:303-313.

Chambers R, Longhurst R, Pacey A (eds.) (1981) Seasonal Dimensions to Rural Poverty. London: Pinter.

Chandra RK (1981) Immunocompetence as a functional index of nutritional status. Br. Med. Bull. 37:89-94.

Chen LC, Chowdhury AKM, Huffman SI (1979) Seasonal dimensions of energy protein malnutrition in rural Bangladesh: The role of agriculture, dietary practices, and infection. Ecol. Food Nutr. 8:175-187.

Cole TJ (1993) Seasonal effects on physical growth and development. In Ulijaszek SJ, Strickland SS (eds.): Seasonality and Human Ecology. Cambridge: Cambridge University Press, pp. 89-106.

El-Nofely A, El-Ghadban HM, El-Masry SA (1993) Arm muscle and fat areas vs. weight/length ratio in the assessment of protein energy malnutrition. Am. J. Hum. Biol. 5:259-264.

Eveleth PB, Tanner JM (1976) Worldwide Variation in Human Growth. New York: Cambridge University Press.

Fratkin E (1991) Surviving Drought and Development: Ariaal Pastoralists of Northern Kenya. Boulder: Westview Press.

Frisancho AR (1981) New norms of upper limb fat and muscle areas for assessment of nutritional status. Am. J. Clin. Nutr. 34:2540-2545.

Galaty JG, Bonte P (1991) The current realities of African pastoralists. In Galaty JG, Bonte $\mathrm{P}$ (eds.): Herders, Warriors and Traders. Boulder: Westview Press, pp. $267-291$.

Galvin K (1985) Food procurement, diet, activities and nutrition of Ngisonyoka Turkana pastoralists in an ecological and social context, doctoral dissertation, State University of New York, Binghamton.

Hamill PV, Dridz TA, Johnson CL, Reed RB, Roche AF, Moore WM (1979) Physical growth: National Center for Health Statistics percentiles. Am. J. Clin. Nutr. $32: 607-629$.

Hilderbrand $\mathrm{K}$ (1985) Assessing the components of seasonal stress amongst Fulani of the Seno-Mango, central Mali. In Hill AG (ed.): Population, Health and Nutrition in the Sahel: Issues in the Welfare of Selected West African Communities. Boston: Routledge and Kegan Paul, pp. 254-287.

Huss-Ashmore R, Goodman JL (1988) Seasonality of work, weight, and body composition for women in highland Lesotho. In Huss-Ashmore R, Curry JJ, Hitchcock RK (eds.): Coping With Seasonal Constraints. Museum Applied Science Center for Archaeology (MASCA), University of Pennsylvania, 5:29-44.

Huss-Ashmore R, Curry JJ, Hitchcock RK (eds.) (1988) Coping With Seasonal Constraints. Museum Applied Science Center for Archaeology (MASCA), University of Pennsylvania, Vol. 5

Jelliffe DB (1966) The Assessment of Nutritional Status in the Community. Geneva: Who.

Jelliffe DB, Jelliffe EFP (1989) Community Nutritional Assessment with Special Reference to Less Technically Developed Countries. New York: Oxford University Press.

Kauffman CA, Linneman CC, Schiff GM, Phair JP (1976) Effect of viral and bacterial pneumonias on cell-mediated immunity in humans. Infect. Immun. 13:78-83.

Kniker WT, Anderson, CT, McBryde JL, Roumiantzeff M, Lesourd B (1984) Multitest CMI for standardized measurement of delayed cutaneous hypersensitivity 
and cell-mediated immunity: Normal values and proposed scoring system for healthy adults in the U.S.A. Ann. Allergy 52:75-82.

Koster FT, Palmer DL, Chakravorty J, Jackson T, Curlin GC (1987) Cellular immune competence and diar rheal morbidity in malnourished Bangladeshi children: A prospective field study. Am. J. Clin. Nutr. 46:115-120.

Leslie PW, Fry PH, Galvin K, McCabe JT (1988) Biological, behavioral and ecological influences on fertility in Turkana pastoralists. In B Whitehead, B Timmermann, R Varady (eds.): Arid Lands: Today and Tomorrow. Boulder: Westview Press, pp. 705-712.

Lindtjorn B, Alemu T, Bjorvatn B (1993) Dietary pattern and state of nutrition among children in droughtprone areas of southern Ethiopia. Ann. Trop. Paediatr. 13:21-32.

Little MA, Galvin K, Mugambi M (1983) Cross-sectional growth of nomadic Turkana pastoralists. Hum. Biol. $55: 811-830$.

Little MA, Johnson BR Jr (1987) Mixed longitudinal growth of Turkana pastoralists. Am. J. Phys. Anthropol. 69:335-344.

Little MA, Leslie PW (1990) Report to the Government of Kenya, Office of the President: The South Turkana Ecosystem Project.

Little RJA, Rubin DB (1987) Statistical Analysis with Missing Data. New York: John Wiley \& Sons.

Loutan L, Lamotte JM (1984) Seasonal variations in nutrition among a group of nomadic pastoralists in Niger. Lancet 1:945-947.

McCabe JT, Dyson-Hudson R, Leslie PW, Fry PH, Dyson-Hudson N, Wienphal J (1988) Movement and migration as pastoral responses to limited and unpredictable resources. In EE Whitehead, CF Hutchinson, BN Timmermann and RC Varady (eds.): Arid Lands Today and Tomorrow: Proceedings of an International Research and Development Conference. Boulder Westview Press, pp. 727-734.

McDowell I, King F (1982) Interpretation of arm circumference as an indicator of nutritional status. Arch. Dis. Child. 57:292-296.

Margo G (1977) Assessing malnutrition with the midarm circumference. Am. J. Clin. Nutr. 30:835-837.

Martorell R, Habicht JP, Yarbrough C, Lechtig A, Klein RE, Western KA (1975) Acute morbidity and physical growth in rural Guatemalan children. Am. J. Dis. Child. 129:1296-1301.

Martorell R, Ho TJ (1984) Malnutrition, morbidity and mortality. In Mosley WH, Chen LC (eds.): Child Survival: Strategies for Research. New York: Cambridge University Press, pp. 49-68.

Martorell R, Rivera J, Kaplowitz H, Pollitt E (1992) Long-term consequences of growth retardation during early childhood. In Hernandez M, Argente J (eds.): Human Growth: Basic and Clinical Aspects. New York: Elsevier Science Publishers, pp. 143-149.

Mata LJ, Urrutia JJ, Albertassi C, Pellecer O, Arellano $\mathbf{E}$ (1972) Influence of recurrent infections on nutrition and growth of children in Guatemala. Am. J. Clin. Nutr. 25:1267-1275.

Mosley WH, Chen LC (1984) An analystical framework for the study of child survival in developing countries. In WH Mosley and LC Chen (eds.): Child Survival; Strategies for Research. New York: Cambridge University Press, pp. 25-45.

Pagezy H, Hauspie RC (1985) Seasonal variation in the growth rate of weight in African babies, aged 0 to 4 years. Ecol. Food Nutr. 18:29-41.

Poskitt EM (1972) Seasonal variation in infection and malnutrition at a rural paediatric clinic in Uganda. Trans. Roy. Soc. Trop. Med. Hyg. 66:931-936.

Rothman KJ (1986) Modern Epidemiology. Boston: Litthe, Brown.

Rowland MGM, Cole TJ, Whitehead RG (1977) A quantitative study into the role of infection in determining nutritional status in Gambian village children. Br. J. Nut. 37:441-450

Satyanarayana K, Naidu AN, Rao BSN (1980) Adolescent growth spurt among rural Indian boys in relation to their nutritional status in early childhood. Ann. Hum. Biol. 7:359-365.

Shakir A (1975) Arm circumference in the surveillance of protein-calorie malnutrition in Baghdad. Am. J. Clin. Nutr. 28:661-665.

Shakir A, Morley D (1974) Measuring malnutrition. Lancet 1:758-759.

Shell-Duncan B (1993) Cell-mediated immunocompetence among nomadic Turkana children. Am. J. Hum. Biol. 5:225-235.

Shell-Duncan BK (1994a) Child fostering among nomadic Turkana pastoralists. In E Fratkin, KA Galvin and EA Roth (eds.): African Pastoralist Systems. Boulder, CO: Lynne Rienner Publishers, pp. 147-164.

Shell-Duncan B (1994b) Determinants of infant and childhood morbidity among nomadic Turkana pastoralists of Northwest Kenya, doctoral dissertation, Pennsylvania State University, State College.

Shelly KJ (1985) Medicines for misfortune: Diagnosis and health care among southern Turkana pastoralists of Kenya, doctoral dissertation, University of North Carolina, Chapel Hill.

Smythe PM, Schonland M, Breretun-Stiles GG, Coovadia HM, Loening WEK, Mafoyane A, Parent MA, Vos GH (1971) Thymolymphatic deficiency and depression of the cell-mediated immunity in protein-calorie malnutrition. Lancet 2:939-944.

Tomkins A (1993) Environment, season and infection. In Ulijaszek SJ, Strickland SS (eds.): Seasonality and Human Ecology. Cambridge: Cambridge University Press, pp. 123-134.

Trowbridge FL, Newton LH (1979) Seasonal changes in malnutrition and diarrheal disease among preschool children in El Salvador. Am. J. Trop. Med. Hyg. 28: 135-141.

Trowbridge FL, Staehling N (1980) Sensitivity and specificity of arm circumference indicators in identifying malnourished children. Am. J. Clin. Nutr. 33:687-696.

Trowbridge FL, Marks JS, de Romana GL, Madrid S, Boutton TW, Klein PD (1987) Body composition of Peruvian children with short stature and high weightfor-height. II. Implications for the interpretation for weight-for-height as an indicator of nutritional status. Am. J. Clin. Nutr. 46:411-418.

Ulijaszek SK, Strickland SS (eds.) (1993) Seasonality and Human Ecology. Cambridge: Cambridge University Press.

Vijayaraghavan K, Sastry JG (1976) The efficacy of arm circumference as a substitute for weight in assessment of protein-calorie malnutrition. Ann. Hum. Biol. 3:229-233.

Waterlow JC, Buzina R, Keller W, Lane JM, Nichman MZ, Tanner JM (1977) The presentation and use of height and weight data for comparing the nutritional status of groups of children under the age of 10 years. Bull. Wld. Hith. Org. 55:489-498.

Ziegler HD, Ziegler PB (1975) Depression of tuberculin reaction in mild and moderate protein-calorie malnourished children following BCG vaccination. Johns Hopkins Med. J. 137:59-64. 